\section{Commentary: Surgery versus stereotactic body radiation therapy for patients with renal dysfunction and non-small cell lung cancer: The answer is still not clear}

\section{Stephanie H. Chang, MD}

Chronic kidney disease (CKD) and end-stage renal disease (ESRD) are increasing, with an estimated CKD global prevalence of $13.4 \%,{ }^{1}$ and the prevalence of ESRD tripling between 1990 and $2018 .^{2}$ This increasing patient population has known poor overall survival, with an estimated 5-year mortality of $55.6 \% .^{3}$ In addition to their higher overall mortality, many patients with renal dysfunction have associated hypertension, diabetes, vasculopathy, and platelet dysfunction from uremia, increasing the risk of postoperative complications.

Saito and colleagues ${ }^{4}$ evaluate the long-term outcome after surgical resection for non-small cell lung cancer in patients with normal creatinine level CKD (defined as nondialysis-dependent CKD), and ESRD (defined as dialysisdependent CKD). ${ }^{4}$ Their data suggest no difference in 30-day mortality, but increased 90-day mortality for ESRD and CKD patients $(3.2 \%$ ESRD vs $3.5 \%$ CKD vs $1.0 \%$ control). Overall 5-year survival was lower in these groups as well, with $52.9 \%$ in the ESRD group, $57.5 \%$ in the CKD group, and $78 \%$ in the control group among all stages. Type of surgical resection (wedge, segment, or lobe) was not associated with a significant difference in recurrence, with a higher rate of wedge resection in the ESRD group.

Although these data are interesting, there are some limitations that should be highlighted. First, the database used did not include estimated glomerular filtration rate, but

From the Division of Thoracic Surgery, Department of Cardiothoracic Surgery, New York University Langone Health, New York, NY.

Disclosures: The author reported no conflicts of interest.

The Journal policy requires editors and reviewers to disclose conflicts of interest and to decline handling or reviewing manuscripts for which they may have a conflict of interest. The editors and reviewers of this article have no conflicts of interest.

Received for publication Nov 10, 2021; revisions received Nov 10, 2021; accepted for publication Nov 17, 2021; available ahead of print Nov 20, 2021.

Address for reprints: Stephanie H. Chang, MD, Division of Thoracic Surgery, Department of Cardiothoracic Surgery, New York University Langone Health, 530 First Ave, Suite 9V, New York, NY 10016 (E-mail: stephanie.chang@nyulangone.org). J Thorac Cardiovasc Surg 2022;164:240-1

$0022-5223 / \$ 36.00$

Copyright (c) 2021 by The American Association for Thoracic Surgery

https://doi.org/10.1016/j.jtcvs.2021.11.034

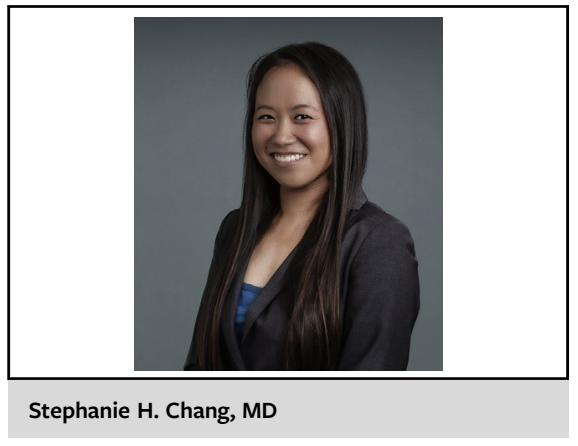

CENTRAL MESSAGE

Further studies are required to determine the optimal treatment for patients with renal dysfunction and early stage non-small cell lung cancer.

only an absolute creatinine level to define CKD, which is not an accurate definition. This registry analysis only includes patients who underwent surgery, with no data regarding patients with CKD or ESRD who underwent stereotactic body radiation therapy (SBRT). This model inherently has bias where perhaps only the more medically fit patients with renal dysfunction underwent surgery, accounting for the minimal difference in 5-year survival between ESRD patients in general and ESRD patients who had lung cancer. Furthermore, there is no subset analysis to determine whether or not patients with CKD or ESRD had different perioperative complications or 90-day survival based on extent of resection.

The important clinical question is: What is the best treatment for patients with renal dysfunction and non-small cell lung cancer? For early-stage patients who can be treated with SBRT versus sublobar resection or lobectomy, further analysis is required to determine the best treatment. SBRT versus sublobar resection shows improved 1-, 2-, 3-, and 5 -year survival in the surgical group, with 71\% 5-year survival in patients who undergo wedge resection or segmentectomy, compared with 46\% 5-year survival in patients undergoing SBRT. Lobectomy has similar reported increased overall survival compared with SBRT. ${ }^{5}$ A follow-up study should be performed that compares control, CKD (using estimated glomerular filtration rate), and ESRD patients who undergo SBRT, wedge resection, segmentectomy, and lobectomy. Although a randomized trial may not be feasible, data analysis should include propensity 
score-matched groups, with evaluation of postoperative complications, short-term mortality, and long-term survival. More recent data collection may affect the complications and short-term mortality because most lung resections are now performed in a minimally invasive fashion, compared with the data collection period of 2010.

\section{References}

1. Lv JC, Zhang LX. Prevalence and disease burden of chronic kidney disease. Adv Exp Med Biol. 2019;1165:3-15.
2. Centers for Disease Control and Prevention. Chronic Kidney Disease Surveillance System. Accessed November 22, 2021. https://nccd.cdc.gov/ckd/default. aspx

3. Nordio M, Limido A, Maggiore U, Nichelatti M, Postorino M, Quintaliani G, Italian Dialysis and Transplantation Registry. Survival in patients treated by longterm dialysis compared with the general population. Am J Kidney Dis. 2012;59: 819-28.

4. Saito T, Murakawa T, Shintani Y, Okami J, Miyaoka E, Yoshino I, et al. Preoperative renal dysfunction and long-term survival after surgery for non-small cell lung cancer. J Thorac Cardiovasc Surg. 2022;164:227-39.e6.

5. Reverberi C, Trovò M. Stereotactic radiotherapy for early-stage non-small cel lung cancer. Mini-invasive Surg. 2020;4:43.
See Article page 227

\section{Commentary: Mitigating lung cancer mortality in patients with end-stage renal disease}

\author{
Aaron M. Delman, MD, MS, and \\ Robert M. Van Haren, MD, MSPH
}

As patients live longer, the presence of significant comorbidities at the time of lung cancer diagnosis has increased. ${ }^{1}$ In particular, the global prevalence of chronic kidney disease (CKD) has increased $29.3 \%$ over the last 30 years and has been associated with greater risks of short-term mortality and morbidity following lung cancer surgery. ${ }^{2-4}$ The rising incidence of $\mathrm{CKD}$ and dialysis-dependent (DD) end-stage renal disease (ESRD) in patients with non-small cell lung cancer requires accurately estimating the impact of preoperative CKD/ESRD on postoperative outcomes. In addition, understanding the long-term association of CKD/ESRD on cancer-specific and overall survival is essential for developing a patient-centered treatment plan for this complex population.

\footnotetext{
From the Cincinnati Research in Outcomes and Safety in Surgery (CROSS) Research Group. Department of Surgery, and Division of Thoracic Surgery, Department of Surgery, University of Cincinnati College of Medicine, Cincinnati, Ohio.

Disclosures: The authors reported no conflicts of interest.

The Journal policy requires editors and reviewers to disclose conflicts of interest and to decline handling or reviewing manuscripts for which they may have a conflict of interest. The editors and reviewers of this article have no conflicts of interest.

Received for publication Sept 21, 2021; revisions received Sept 21, 2021; accepted for publication Sept 22, 2021; available ahead of print Sept 27, 2021.

Address for reprints: Robert M. Van Haren, MD, MSPH, 231 Albert Sabin Way, ML0558, Medical Sciences Building, Room 2472, Cincinnati, OH 45267-0558 (E-mail: vanharrm@ucmail.uc.edu).

J Thorac Cardiovasc Surg 2022;164:241-2

0022-5223/\$0.00

Published by Elsevier Inc. on behalf of The American Association for Thoracic Surgery

https://doi.org/10.1016/j.jtcvs.2021.09.037
}

Check for updates

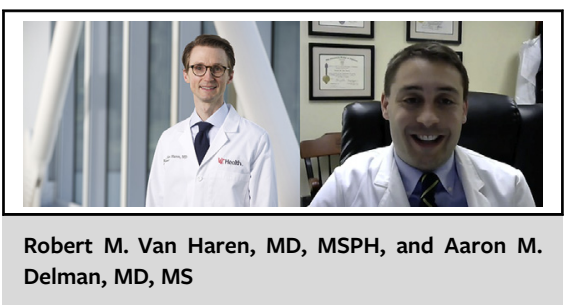

CENTRAL MESSAGE

Lung cancer resection in patients with preoperative renal dysfunction can mitigate cancer-specific mortality.

Saito and colleagues, ${ }^{5}$ in this issue of the Journal, tackle this dilemma and investigate the relationship between preoperative CKD/ESRD and long-term survival after lung cancer resection. Using the Japanese Joint Committee of Lung Cancer Registry, they were able to identify a nationwide cohort of 16,377 patients who underwent resection for non-small cell lung cancer in 2010. Patients were then stratified by renal function status before surgery, ie, control, nondialysis-dependent (NDD)-CKD, and DD-ESRD, and outcomes were compared between groups.

The authors identified NDD-CKD and DD-ESRD as independent risk factors for all-cause mortality following lung cancer resection. Interestingly, when separating out cancer-specific mortality, there was a stark difference in the cause of death between cohorts. Only $29.7 \%$ of patients with DD-ESRD and $51.0 \%$ of NDD-CKD experienced cancer-specific mortality, which was lower than 